\title{
Social Theory and the Study of Computerized Work Sites
}

\author{
Bruno Latour \\ Centre de Sociologie de l'Innovation \\ Ecole Supérieure des Mines de Paris
}

\begin{abstract}
This paper is a meditation written by an ignorant trying to understand what has changed in his field, social theory, because of the development of information technology and because of the analysis of sociologists, specialists of labor relations, of organizations, of situated cognition, etc. It starts with a simple example of practice and tries to analyze it by following new concepts which seem to derive from the redistribution of humans and non-humans due to the pervasiveness of computerized work sites. It then tries to list the services rendered to social theory by the studies made by much more knowledgeable colleagues. Finally, it tries to show, with a very clumsy vocabulary, how we could account in better terms than networks, for a social theory redistributed by information technology and its students.
\end{abstract}

\section{PROLOGUe}

"Let us meet at 12:30 at the Eurotunnel Gate at Waterloo Station," I had told Adam on the phone from Paris. "All right. I will be there," he had said, approving this quasi contract with the telephonic equivalent of a hand shake or of a signature. I could have asked him to send a confirmation fax to make doubly sure that we had agreed on the same information in spite of the one hour lag that England insists on having over the Continent (to feel closer, I guess, to the United States). But since we are friends and not business partners, our word is our bond. While I am sitting on the train, the sentence we have both uttered a few hours before has changed its position quite a bit. It is now hovering over me (and, I hope without being certain, over him as well) to offer both of us a program of action which allocates roles to two individual designated by the same first name "Adam" and "Hélène," and to make these individuals circulate in a space and time trajectory marked by land marks - Paris, London, Waterloo Station (not such a nice label, by the way, for welcoming a French woman) - and by other types of marks like gate names or numbers and hands of clocks indicating 12:30 (of course I did not mention that it was 
p.m. and not a.m., relying on his implicit knowledge of what is "of course" and goes without saying, but of this I am no longer completely sure while I am fretting on the comfortable seat).

Reading through the Chunnel, I go through a sort of out-of-body experience, a very common one, since there are now at least two Helène $s$, the one sitting there and the other one anticipated by the agreed upon program of action and which is due to meet Adam at the expected time and place an hour from now (twenty minutes if the bloody Brits had managed to modernize their line as speedily as the French!). When we meet one another, I will not only be reunited with Adam, but the Adam-of-the-script will coincide with the Adam-in-the-flesh and the Helène-of-the-script will meet Hélène at the Eurotunnel Gate which will be, if everything goes well, the same as the gateof-the-script. The coincidence is a risky one, though. The train might be delayed - possible Waterloo debaptised to please the French and renamed "Austerlitz" - quite unlikely - Adam might be late - more likely. It is only when all the conditions of felicity will have been fulfilled that we will forget about the script hovering over us and, after a friendly kiss, head for the National Gallery.

\section{DIFFERENT TYPES OF DELEGATES}

What does this anecdote have to do with natural or artificial intelligence, information technology and with organizations? A lot as we will see later, but we need to analyze it first by unfolding its various threads.

Over the phone, Hélène and Adam have told each other a story about London, trains, stations, Waterloo and about visiting the National Gallery, a story which, by itself, is no different from daydreaming or novels. They have together, one pushing the other, invented a possible world in which they could meet, be friends again (see, for instance, Pavel 1986). In the course of the story they delegated characters also called "Adam" and "Hélène" which could do things, and meet and talk and follow a certain path inside a background of land marks which were also called "London," "Waterloo" and "Trafalgar Square." In such a way they went through another out-ofbody experience since they lent to their story characters, in part similar to them in part different, who were doing new and impossible things in this other frame of reference. As in the Allen film, where Bogart takes over the conversation of the too clumsy Woody, they duplicated themselves, adding a set of clones to their own selves.

The story, however, took a completely different meaning when they decided over the phone that it was no longer a possible world that they had populated until then with similes of their own bodies, but that, on the contrary, they were binding themselves to a program of action, a script which was, from now on, delegating roles and trajectory to them. ${ }^{1}$ They were organizing a joint trip to London. The script has become the dispatcher of their future activity, and they had now to fulfill the roles allocated to them, although, a few minutes ago, they were sending characters resembling them in another space and time. Without changing much of its material content, the story which they were telling each other has become an organization. They could change it at

\footnotetext{
'See, for instance, Taylor (1993). See also the work of Barbara Czarniawska on organizations as peculiar forms of discourse.
} 
will, but now that the telephone has been put down, and that they have no way to ring one another, the script takes over and limits their ability to maneuver. Hélène and Adam in the flesh are now the delegated characters of their own story - but that's the point, the story is no longer their own.

Characters in the story may change, and it is because they change so much, shifting quickly out to other times, spaces and actants that they deploy so many possible worlds, worlds which were not even envisioned a few minutes ago. Characters in the script dispatch roles, appointments, performances in a space and time trajectory which is also going to produce novelty but not of the same kind as that of the story. Instead of possible worlds, the dispatching is going to actualize one world, the one where Adam in the flesh meets Hélène in the flesh at 12:30 in London by distributing agents and functions in a spatial and temporal trajectory.

The script that dispatches activity to make one possible world actual is too weak in itself to bind its delegated characters to it. The bonds of legal ties have to be added to transform this script into a quasi-contract that will make sure that the personality and wishes of Adam and Hélène will be stable over the period of time and the span of space that separates them from their kissing each other. The characters of the story and of the script are now tied up with chains that cross beyond the limits of space and time. Of course, since they are friends they do not need to instrument these ties with so many faxes, signatures, attorneys at law, lawyers and paperwork. An "all right" on the phone is all it takes to insure the isotopy of all those characters through time and space. Helène is confident in Adam; she recognized the sincerity of his voice and his tone of indisputable engagement; his track record so far has been impeccable. Friendship and confidence are enough to carry the will through space and time without too much deformation. Lawyers and paperwork could become visible, however, if things went wrong, trains crashed, homicide were committed, Helène kidnapped, etc. Traces of this informal quasi-contract would be elicited from telephone companies, Eurotunnel computers, wiretapping, and so on, to prove that they had planned a meeting (detectives are good at finding the most implausible traces of informal exchanges and turn out evidence no one expected).

To the story, to the script, to the bonds of quasi-contracts, Adam and Hélène have added references to places and times like Waterloo Station or the Eurotunnel Gate. They do not bring those actants in their scripts, they allude to them through a form, a name, a description that carries no resemblance whatsoever with what they talk about but carries information about them. More delegates standing for Waterloo Station and London and which circulate in such a way that some path is thus established through space and time could retie those forms back to what they refer. ${ }^{2}$ Hélène, who has never been to Waterloo Station, will not be able to recognize the station but will be able to read the large letter signs that are written all over the platform of her destination, W-A-T-E-R-L-O-O. She will know she is at the right place because of the correspondence between the piece of information she has jotted down and the big signs she can now see through the window. Correspondence but not resemblance is what will lead both of them through those blind referential chains. (Adam, however, being a Londoner, will not even look at the labels but will simply fall back on an old embodied routine and walk through the

${ }^{2}$ For an example in a science field, see Latour (1995). 
streets from his studio to the Station, adjusting from time to time, without even thinking, to the few roadblocks along the path, just doing next what comes naturally). ${ }^{3}$

Who talks over the phone? Who travels to London? Not Adam and Helène only. Talking from Paris to London would require a very loud voice and walking and swimming from one point to the other would require quite a good breath and an athletic body, and a lot of time, and Hélène will age quite a bit through this strenuous effort and may drown along the way. Adam, Hélène, and electrons, and digits and telephone companies are doing the talking. Hélène and the trains and SNCF and Eurotunnel are doing the traveling. Delegates again by the millions which are taking over the tasks of talking and traveling and afford, allow, permit, authorize Adam and Hélène to rejoin. Not, to be sure, this Hélène and this Adam, but an Adam and $a$ Hélène among the many they have statistically anticipated and for whom they have designed telephones and seats and fares and week-end packages - breaking down consumers in small socio-professionnal categories through fine tuned marketing, averaging out body sizes and weights through clever ergonomics. For this Hélène, the millions of delegates count for naught: she just boards the sleek train, but they act all the same; as for the Eurotunnel, it is Helène who is just one passenger among (they hope) millions of others, one user's input at the ticket counter keyboard (although the hostess has been asked, in a training program set up by a public relations outfit, to smile so as to "personalize" the anonymous relation).

The rail tracks, the telephone lines, the software, the beautiful umbrella of Waterloo Eurostar Station, the seats are reliable and steady not because they form the outside world in which Helène's human interaction with Adam takes place but because each of them rely on other actants which have a different timing. ${ }^{4}$ The silicone of the chips, the steel of the dome, the plastic foam of the seats, are coming from far away in space and time and continue to act, dislocated, rearranged, recombined, offering a steady background to the fleeting interaction where these two youngsters kiss one another for a fraction of a second at the Eurotunnel Gate. The couple can change their plans or cancel their trips, but the chips, the steel frame, the carriage will last a bit longer, if, that is, inspectors, engineers, and maintenance crews keep them up according to schedule. To the intersubjectivity of their relations, one should add the interobjectivity of all these folded delegates they rely on so much (Latour 1994b).

We met the Hélène-on-the-phone, which we called "in the flesh" to simplify, then the Helène character in the story who was going to London, then the Helène delegated by the script which was supposed to fulfill the role expected from her, then the Hélene stabilized through time and space by the bonds of contracts and engagements, then the many statistical Hélène-like customers and consumers inscribed in the systems, marketing and fares of the telephone and railways companies. Quite a lot of Hélènes! And all this without mentioning those Hélènes anticipated by Adam who might bear much more resemblance with idols of dreams and flesh conjured, through crystallization and condensation, out of a vast array of mothers, bodies, animals and djinns, than with the beautiful, fleeting and unsteady Hélène walking out of the train in her red coat smiling through her deep blue eyes.

${ }^{3}$ On the routine nested inside an organization, see the classic book by Suchman (1987).

${ }^{4}$ On the notion of technical delegates, see Latour 1994a. 
Then we had the many delegates that travel back and forth through the referential chains allowing places, actants and times to be carried over in the various forms and accounts and then back again to where they came from - and this was without counting the metrology that makes possible, at great expense, to connect the clocks all over Europe so that the large mechanical one of Big Ben, across the River Thames, coincides with the high-tech digital clock over the gate and with Adam's own watch, at which he is nervously glancing. Present through the steady mediations of bricks, steel, software, door closers, counters and elevators, hundreds of engineers, workers, designers, architects, bureaucrats, and millions of past parts are sharing the interactions with the couple, present, hic et nunc, and now reunited. Present and absent, silent and meaningful, those other kinds of delegates organize in advance, indicate, force, forbid, afford, allow the zigzagging path that the two friends are now drawing over the white lobby floor to exit Waterloo station.

\section{IN WHAT KIND OF WORLD DO COMPUTERIZED WORK SITES EXIST?}

The kind of world I tried so clumsily to describe, by following the paths of delegation instead of its components resembles the two former ones in which computing has been successively, and somewhat successfully, inserted but it also differs from them in a few crucial features. The first one took the humans as irrelevant; the second tried to circumscribe the non-humans as much as possible. The third follows, as far as possible, and in all its consequences the impossibility of allocating humanity and non-humanity in the first place. ${ }^{5}$

The first world was that of efficient machines, accurate facts, and profitable markets that were produced by human subjects almost entirely reducible to calculations, to the point where no one could distinguish a calculation made inside a human machine from an automatic human outside of a body. In such a world, to be sure, there subsisted a few pockets of disorder, passion, feelings, and politicking, but they were just that, pockets, which should, like ponds after a storm, dry up under the warm and clear sun of Reason. Dreams of clarity proliferated from the principle of universal calculability, to automated factories, transparent communication, cybernetic feedback, robots finally embodying the disembodied conceptions of reason devised by so many philosophers who did not know that they were, long before chips and silicon, talking about computers when they reformed minds, mores, societies and mathematics. ${ }^{6}$ For a moment, in the fifties and sixties, the coincidence of philosophy, brain sciences, social reforms, world markets and the advent of computers seemed so powerful that this dream of absolute clarity was shared by everyone (I mean the few who believed they counted for everyone).

Dreams of clarity are dreams all the same: that is, fuzzy and blurred. Fuzziness seemed soon to creep in and "softies" took over introducing us to a second picture of the world. Computers have bugs; software engineers are a rather unmanageable lot; organizations are so flaky and so fickle that many big systems crashed; human experts seemed to have at the tips of their fingers many things that could not easily pass through the keyhole of the keyboard; lawyers have an uncanny

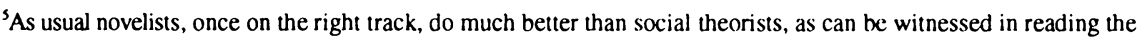
extraordinarily subtle book by Powers (1995). I thank Geff Bowker for this reference and for many others.

${ }^{6}$ This is made clear in Gardner (1985), as well as in many articles by Phil Agre.
} 
ability to get back into the lines of software with litigation and copyright laws; clients obstinately refused to clearly state the specifications they wanted implemented or, believing in the ease and transparence that was so much trumpeted around, constantly asked for changes and new features. The picture, like in a background/foreground Gestalt shift, was suddenly reversed and computer technologies, expert systems, and information sciences appeared as little pockets, tiny microtheories, small and fragile experiments, inside a human, organizational, social and political mess which gave no sign of slowly fading away. Opacity grew instead of transparence. All those black boxes piled on top of one another inside soft organizations and shifting markets, made for an even more obscure imbroglio.

The human dimension had been forgotten, it was said. ${ }^{7}$ The subjective, intentional, interactive human was said to be back (for an impressive study, see Lave 1988). Organizations and political forces have to be taken into account, it was argued, since they offered the background and logistics of those computer systems. After the triumph of engineers in the first world, were we witnessing the revenge of sociologists, psychologists, ethnographers, hermeneuticians, management experts, organizational scientists and other "softies" to give us a picture of the second?

I do not think so. The field is already much further than the defense of humanity inside microchips. The works by Susan Leigh Star on computerized work sites (see, for instance, Star 1989), of Ed Hutchins on cognitive anthropology (Hutchins 1995), of Lucy Suchman and Charles Goodwin on coordination into work sites, ${ }^{8}$ of Laurent Thévenot (1994) on familiar courses of action, in addition to the studies by social historians of science, ${ }^{9}$ and sociologists of science turned to organization like John Law (see, in particular, Law 1993), point to a complete redefinition of the divide between the two worlds. In the following statement, "information science and artificial intelligence in human organizations," only the two couplers "and" and "in" have remained unscathed! Each of the six other words have been reformatted beyond recognition. Neither the first nor the second picture of the world seems to be able to handle those changes. The paradox is that there are still people who advocate - or fear - the development of those terms although the practical result of their introduction has been to completely dismantle each of them. ${ }^{10}$

Take the human, for instance. Of course, it is no longer a calculating entity which could easily be morphed into silicon chips. But it is certainly not a subjective, reflexive, intentional, embodied unity either. Not only has its cognition been distributed, situated, but it is now shared with many intellectual technologies to the point where studying a human is studying a field of forces and transfers of documents, instruments, ideographies, through a collective of similarly distributed fellows, some of them look anthropomorphic but many don't. The engineering dream was to morph the human into a rational machine. The humanist counterdream was to recover an

${ }^{7}$ For the general public, at least, this position is well represented by Dreyfus (1992).

${ }^{8}$ See, for instance, the marvelous piece on cognitive group work in an oceanography ship by (ioodwin (1995).

\footnotetext{
${ }^{9}$ Among which that of Simon Schaffer stands as particularly compatible with those of sociologists of labor and computerized work sites; see among, Schaffer 1994.
}

${ }^{10}$ As can be seen in reading Collins (1990), who tries to patrol a boundary as fractal as that of Bosnia. 
intentional, reflexive and coherent carrier of values. The result is a rather bizarre cyborg that resembles neither the machine nor the human. ${ }^{11}$

Intelligence has undergone changes which are as drastic. With so many intellectual technologies being introduced from writing to laboratories, from rulers to pebbles, from pocket calculators to material environments, the very distinction between natural, situated, tacit intelligences and artificial, transferable, disembodied ones has been blurred. Intelligence no longer seems a psychological or even a cognitive property, but something more akin to heterogeneous engineering and world making, a distributed ability to link, associate, tie, fragments of reasoning, stories, action routines, subroutines, and to hang them to many holders; some of them look like neurone nets, other like software, other like graphics, still other like conversations and rituals.

Artefacts themselves have changed to the point where neither engineers nor sociologists would recognize them any more. Machines, automatisms, material components were supposed to be asocial and ahistorical. This is why they fascinated so much the engineers dreaming to delegate to them the flesh and blood of the disorderly bodies and why social scientists and humanists worried so much about their barbaric introduction into the civilized world. But artefacts, in turn, have become active social actants endowed with a history and a collective career, shifting competencies and affordances back and forth between one another and between the (by then deeply) redistributed human agents (Latour 1992). They enter the collective, not because they close the mouth of intentional humans, stop the controversies of squabbling scientists, bring passive resources to the inventive mind, offer a convenient receptacle for social values, but, on the contrary, because they add intentions, controversies, activities, meanings to programs of action that would be, without them, too limited and narrow.

For political reason, science had offered, for several centuries, the common blueprint to picture the human mind, its natural intelligence, and that of matter and artefacts. But what is left now of the former vision of an asocial, ahistorical science, hovering away and above the collective brew of passions and politics? The sciences too have been reformatted beyond recognition without losing the reality and objectivity they were so much boasting about. Many new realities and objects are brought in through the referential chains launched by fragile disciplines inside narrow, local, tiny, expensive and blind networks of practice which establish connections with totally unexpected entities which, from now on, have a different history and form a different society (for one example of this complete change, see Smith and Wise, 1989). Clever delegates, sophisticated instruments, tiny non-human observers are now populating those relativistic networks animating society and history with fresh actants. Being real and objective in addition no longer makes them so many foreign bodies in the social fabric. They simply add to its complication, to the intricacies of its political representation.

Information takes a different meaning if the sciences are thus reconfigured. A form cannot be what it is the form of. The words "Waterloo Station" are not Waterloo Station any more than a map is the territory, but it is what allows Hélène in Paris to establish at a distance some connection between Paris and the place of her rendezvous. It does not bridge the distance

\footnotetext{
"As can be witnessed in reading Haraway (1992).
} 
because it would carry nothing from the Station to her flat since nothing that resembles the building would travel in such a way. But it is not a conventional or mnemonic sign standing arbitrarily for the real Station either. It is only one transformer into a long chain of similar transformers that will cross through the various matters of expression allowing a constant to be maintained through the continuous shift of delegates and translators. Words never face the world, they never mirror nor conventionally relate to "it." Worlds may be shaped in such a way that many types of expression, including words, may trace a referential path within it, allowing action at a distance. Information does not draw a virtual world added to the first; it is deeply rooted in it, part of it, risky paths linking entities to one another through the peculiar grasp of reference.

Organizations, finally, no longer look the same now that to their local interactions, and to their dispatchers, has been added so many computers and data banks, so many artefacts and intellectual technologies, so many stories, so many centers of calculation and information processing rooms, so much distributed and situated cognition. It is no longer clear if a computer system is a limited form or organization or if an organization is an expanded form of computer system. Not because, as in the engineering dreams and the sociologists nightmares, complete rationalization would have taken place, but because, on the opposite, the two monstrous hybrids are now coextensive. If instead of Helène going to London to meet Adam, I had told the story of a GOTO function in BASIC programming language - the only one I know to my great shame - we would have encountered as many legal, material, social, and referential features. Exactly as following Hélène forced us to get out of her interaction with Adam to take into account many other paths through many other types of delegations, following the realization of software instructions will have taken us out of chips and gates through many heterogeneous paths.

Thus, if I am correct in recapitulating all those changes, to follow "information science and artificial intelligence in human organizations" no longer means to try to expand rationality everywhere, nor does it mean to try to limit its expansion by insisting on the human dimension of all personal interactions and on the irreducible irrationality of work sites. The world in which computing occurs has too many unexpected features, many of which have been revealed to social theory and philosophy by the attempts to develop computer systems according to the politics of reason and by the failures to do so.

\section{TYING THE FRAGMENTS BACK TOGETHER}

One description of this third world into which the study of computerized work sites has introduced us, is to say that computer systems are no more embedded in human organizations than human organizations can be embedded in computer systems. Embedding is not a good metaphor to follow the many displacements that have modified beyond recognition definitions of labor, expert, information, communication, computing, simulation and institutions. But how to follow those displacements?

One way of talking about displacements without using structures and essences is, of course, to consider that fragments are the only thing we have to consider: fragments of intelligence distributed through machines, fragments of machines dispersed through bodies, fragments of organizations morphed into software lines, fragments of codes sticking into institutions, fragments of subjects floating into virtual space. Much of the cyborg literature looks to me as an appeal to 
the inevitable fragmentation of bodies, organizations, subjects, science, artefact, markets and stories.

Are fragments, however, so different from the structuralist position they wish to disseminate? This is not certain. The fragment has the same differential property as the element of the bygone structure. In the same way as an item in a structure is defined only by its difference in a list of substitutable items, a fragment takes its meaning only from its position in the system of transformations it alludes to. The only difference between the construction of structuralism and its deconstruction into fragments is that there is no longer any structure to compose the list of substitutions. Thus, fragments are structural features without structure! This might be a way of accumulating the disadvantages of the rationalism that has been criticized without keeping any of its enlightening features. ${ }^{12}$ If we accept the deconstruction metaphor, the relish in fragmentation, so pervasive in postmodern writings, is simply, under the guise of modesty, a way of prolonging modernism a bit longer without running the risk of shaping a vast and fragile system.

This is, of course, why we talked so much of networks (or better rhyzomes in order to avoid the technical connotation of the word). ${ }^{13}$ First because it was a way, as powerful as structures, to fight essences. A new software package, a new computer site, a new chip, a new anti-trust policy, a new electronic forum will not be seen as having to do with technology, or labor organization, or culture, or law but as the heterogeneous branching out of a rhyzome. This is a useful way of talking since it does not require, at the beginning, a definition of what it is to be a skilled human worker, or an efficient organization, or a body of expertise, or an automaton, or an enterprise. Each element in the network is simply defined by the heterogeneous list of its associates. A consumer of bank services is redefined by "its" association with the automatic bank teller exactly as the definition of an Intel chip is modified by being associated with a new software or an Army weapon system. An expert knowledge is simply reformatted and reconfigured once it has been in part written down in an expert system inside a stock management package. A fuzzy logic gate, once inserted into a washing machine in a Korean factory to win through advertisement a new market share, is simply another heterogeneous connection that reformats fuzzy logic as much as Korean markets. Essence is existence, and existence is association.

The second advantage of a network is that it radically differs from a structure - fragmented or not - since it defines entities not by the substitutability of other differential positions but by the list of unsubstitutable and wholly specific associations of elements that make it up. Instead of being composed out of differentials - following the linguistic metaphor that held structuralism together - a network is made up of actants, each endowed with its unique specificity, hence its use in following historical and local trajectories to a degree of precision unknown in the

\footnotetext{
${ }^{12}$ As Serres (1995) puts it, "The larger is the [vase] the more fragile it is. If you break it, the smaller the fragment is, the more resistant it is. Consequently, when you create a fragment, you seek refuge in places, in localities, which are more resistant than a global construction.... The philosophy of fragments brings together the philosophy of the museum and the museum of philosophy; thus, it is doubly conservative" (p. 120).

${ }^{13}$ For a recent analysis, see Callon (1992). The word "rhyzome" being, of course, from Deleuze and Guattari (1972/1983). Deleuze being certainly the most interesting philosopher, in that respect, since he always lived in this third world. For an excellent presentation, see Zourabich vili (1994).
} 
structuralist literature. ${ }^{14}$ In a network, each item is, so to speak, an independent mediator instead of a differential at the intersection of paradigmatic and syntagmatic lists, a mediator being defined as an event which is neither completely a cause nor a consequence.

Rhyzomes and heterogeneous networks are thus powerful ways of avoiding essences, arbitrary dichotomies, and to fight structures. But if they provide the analyst with a degree of freedom and with an agnosticism as large as those he or she is following around, their limit is to define entities only through association. Their flexibility is at once their main advantage and their main disadvantage. Powerful against structures as well as essences and moralizing, they become empty when asked to provide policy, pass judgement or explain stable features. Talk of rhyzomes allows the analyst to avoid revolution talks, technological fix talks, hypes of many sorts and is good at showing, for each innovation, the ordinary bricolage which makes it up. It also allows us to connect fragments together in the freest way. However, this is precisely where the weakness of rhyzomes lies: they are critical of every move, including of course the denunciatory tone of the critique, but they remain critical tools, good only at distributing, undoing, deploying, disseminating. Their dissolving power is so great that after having dissolved the illusions of critical postures, there is not much that is left and they even may turn into a somewhat perverse enjoyment of the diversity, perversity, heterogeneity and multiplicity of the unexpected associations they deploy so well.

This is why something else has to be added to the network to make them useful in following displacements without seeing them as so many fragments, something which they always had in practice but not explicitly - certainly not in so called actor-network theory anyway. ${ }^{15}$ This supplement cannot of course be a return either to essences or to structures, nor can it be a specification of the types of associations in which entities are entangled, since, by definition, the number of types will be as large as the multiplicity of associations. The power of networks would be lost if one had to embark on the impossible dream of listing what kind of linkages are allowed and which are forbidden or impossible. A mad socio-logic would succeed the former mad dream of logicians.

Anne-Marie Mol and John Law (1994) have offered the useful notion of fluid to name this supplement which sticks firmly to the steel frame of networks but adds movement to it. Essences are not redefined only by the list of their associations but also by the fluid that distributes through them. Michel Callon (1995) proposes to reuse the economists' expression of modes of coordination in order to follow, not what is above or beneath the networks, but what traces them. In the prologue and the first section I tried, very tentatively, to introduce different regimes of delegation in order to follow at once the dissemination of an indefinite number of entities and the limited number of ways in which they grasp one another. Whatever the expressions, the attempt is the same: to keep the freedom of rhyzomes - against the modernist urge at rationalization and the postmodernist delight in fragments - but to overcome the limits of actor-networks in specifying the trajectories traced by those free associations.

\footnotetext{
${ }^{10}$ This is also what explains the virtual merging, in science studies at least, between social history and sociology of scientists at work.
}

${ }^{15}$ I would also apply this critique to my own work (Latour 1988). 
I might have exaggerated the impact of information technology on social theory and the needs for revision. Rationality, humanism, structures, fragments, networks, all of those might be useful in describing some of the computerized work sites with which we are faced. I just wanted to explore another possibility: if we had to describe those imbroglios of computer chips, organizations, subjectivity, software, legal requirements, routines, and markets without using modernist or postmodernist idioms, how would we proceed?

\section{REFERENCES}

Callon, M. "The Dynamics of Techno-Economic Networks." In R. Coombs, P. Saviotti, and V. Walsh (Editors), Technical Change and Company Strategies. London: Academic Press, 1992.

Callon, M. Réseaux et coordination (in preparation). "Representing Nature, Representing Culture." Opening Address of the Center for Social Theory and Technology, University of Keele, March 1995.

Collins, H. Artificial Experts: Social Knowledge and Intelligent Machines. Cambridge: MIT Press, 1990.

Deleuze, G., and Guattari, F. Anti-Oedipus, Capitalism and Schizophrenia. Minneapolis: University of Minnesota Press, 1972, 1983.

Dreyfus, H. L. What Computers Still Can't Do. Cambridge: MTT Press, 1992.

Gardner, H. Mind's New Science. New York: Basic Books, 1985.

Goodwin, C. "Seeing in Depth." Social Studies of Science, Volume 25, Number 2, 1995, pp. 237-284.

Haraway, D. "The Promises of Monsters: A Regenerative Politics for Inappropriate/d Others." In C. N. L. Grossberg and P. A. Treichler (Editors), Cultural Studies. New York: Routledge, 1992, pp. 295-337.

Hutchins, E. Cognition in the Wild. Cambridge: MIT Press, 1995.

Latour, B. Aramis, ou l'amour des techniques. Paris: La Découverte, 1992. Translated by C. Porter, Cambridge: Harvard University Press, 1996.

Latour, B. Irreductions part II of The Pasteurization of France. Cambridge: Harvard University Press, 1988.

Latour, B. "On Technical Mediation." Common Knowledgem Volume 3, Number 2, 1994a, pp. 29-62.

Latour, B. 'The 'Pédofil' of Boa Vista: A Photo-Philosophical Montage." Common Knowledge, Volume 4, Number 1, 1995, pp. 144-187. 
Latour, B. "Une sociologie sans objet? Note théorique sur l'interobjectivite." Sociologie du travail, Volume 36, Number 4, 1994b, pp. 587-607.

Lave, J. Cognition in Practice, Mind, Mathematics and Culture in Everyday Life. Cambridge, England: Cambridge University Press, 1988.

Law, J. Organizing Modernities. Cambridge, England: Blackwell, 1993.

Mol, A., and Law. J. "Regions, Networks, and Fluids: Anaemia and Social Topology." Social Studies of Science, Volume 24, Number 4, 1994, pp. 641-672.

Pavel, T. Fictional Worlds. Cambridge: Harvard University Press, 1986.

Powers, R. Galatea 2.2. New York: Farrar, Strauss and Giroux, 1995.

Schaffer, S. "Babbage's Calculating Machines and the Factory System." Des manufactures à la facture des connaissances. Paris: INSERM, 1994.

Serres, M. Conversations on Science, Culture and Time (with Bruno Latour). Ann Arbor: The University of Michigan Press (Translated by Roxanne Lapidus), 1995.

Smith, C., and Wise, N. Energy and Empire: A Biographical Study of Lord Kelvin. Cambridge, England: Cambridge University Press, 1989.

Star, S. L. "The Structure of Ill-Structured Solutions: Boundary Objects and Heterogeneous Distributed Problem Solving." In L. Gasser and M. N. Huhns (Editors), Distributed Artificial Intelligence. London: Pitman, 1989, pp. 37-54.

Suchman, L. Plans and Situated Actions: The Problem of the Human Machine. Cambridge, England: Cambridge University Press, 1987.

Taylor, J. R. Rethinking the Theory of Organizational Communicatoin: How to Read an Organization. Norwood, New Jersey: Ablex Publishing, 1993.

Thévenot, L. "Le régime de familiarité. Des choses en personne." Genèses, Volume 17, 1994.

Zourabichvili, F. Deleuze, une philosophie de l'événement. Paris: PUF, 1994. 


\begin{abstract}
About the Author
Bruno Latour was trained as a philosopher and an anthropologist. After field studies in Africa and California, he specialized in the analysis of scientists and engineers at work. He has written Laboratory Life and Construction of Scientific Facts (Princeton University Press), Science in Action and The Pasteurization of France (both at Harvard University Press). He recently completed a new field study on an automatic subway system, Aramis or the Love of Technology (to be published by Harvard), and an essay on symmetric anthropology, We Have Never Been Moderns (Harvard University Press). He has just published La clef de Berlin, a series of essays on science and techniques. He is professor at the Centre de sociologie de l'Innovation in the Ecole nationale supérieure des mines in Paris.
\end{abstract}

